\title{
Travel Time Estimation as a Global Trend in the Analysis of Innovative Transportation Projects
}

\author{
Alexey Romanov ${ }^{1}$, Maria Lyakina ${ }^{*}, 1$ \\ ${ }^{1}$ Emperor Alexander I St. Petersburg State Transport University, Faculty of Economics \& Management, Department of Transport \\ Economics. 9, Moscovskiy pr., 19003, Saint-Petersburg, Russia
}

\begin{abstract}
Research background: The problem of evaluating the results of innovative transport technologies is extremely important for their implementation and realization. The assessment of possible benefits of innovative transport projects is complicated by a number of circumstances. These include a wide range of arising effects in various forms and the long life cycle of the project, which increases the difficulty of reliably measuring the various costs and results. Thus, it can be argued that outdated approaches and methods for assessing the new transport products hinder the development of innovations.

Purpose of the article: to identify directions for assessing the travel time value in the analysis of the transportation projects economic efficiency.

Methods: The study was conducted by means of scientific methods such as the comparative analysis, system method, generalization and abstraction. Also, we use the results of expert assessments based on depth-in interviews.

Findings \& Value added: The article substantiates the necessity of taking into account the incremental benefits for passengers from travel time reduction as the most important aspect of transport projects implementation, ensuring the formation of the whole range of external social and economic effects;

The multi-factor dependence of the travel time value for a passenger, which is characterised by its heterogeneity during a journey, has been substantiated. The necessity of assessing changes of travel time values in the general transport costs of passengers has been substantiated, taking into account the several factors that lead to different time values.

A visual model of the socio-economic effects formation of the HSR project, caused by changes in the passengers' total transport costs and increased transport accessibility of the region, is proposed.
\end{abstract}

Keywords: Appraisal; value of travel time savings; cost-benefit analysis; costeffectiveness analysis; transport projects;

JEL Classification: R41, O18, F65, B41.

\section{Introduction.}

The problem of choosing relevant economic evaluation tools is extremely important for the implementation of investment projects. The choice of the most profitable investment option is often complicated by a wide range of arising effects, some of which are cannot be valued in monetary terms. A further complication is duration of large projects' life cycles, which makes it difficult to obtain a reliable assessment of the various costs and benefits. These factors make it necessary to improve the existing approaches to the economic evaluation of investments, especially when the project includes the introduction of innovative technologies, the benefits of which are ignored by the standard methods.

Primarily, we are interested in the reflection of socio-economic externalities in the evaluation methods for transport projects - the range of the arising effects, tools for their analysis and subsequent interpretation in the general scheme of investment justification. In particular, we will separately consider the procedure of economic evaluation of benefits from

\footnotetext{
* Corresponding author: malyakina@mail.ru
} 
the reduction of travel time, how this category of effects is taken into account in the presented methods, and how it correlates with concepts of the microeconomic theory.

The problems of determining the value of time resources are studied in the works of (Batley et al, 2019), (Hensher, 2011), (Kovacikova et al, 2018), (Lyons et al, 2007), (Meunier and Quinet, 2015), (Ojeda-Cabral et al, 2018), (Wardman et al, 2015).

However, the results of researches are not always reflected in the practical methods of economic evaluation of transportation projects. The paper compares a number of methodological recommendations for evaluating transport projects with the results of current researches in order to identify areas for improving the tools of economic analysis.

We are primarily interested in solving this problem when evaluating high-speed rail projects, characterised by significant external socio-economic effects, in the determination of which approaches to estimating the benefits from reduced travel times occupy a significant place.

\section{Review}

In world practice, methods such as cost-benefit analysis and cost-effectiveness analysis are most commonly used in the evaluation of transport investments. A. Atkinson (Atkinson and Stiglitz, 1980), E. Mishan (Mishan and Quah, 2020), E. Gramlich (Gramlich, 1981), B. Hansen (Hansen et al., 2004) made a significant contribution to the development of key provisions of cost-benefit analysis. This method compares costs and benefits of specific investments for further decision on the most profitable project implementation. The appraisal procedure generally consists of the following steps:

- determination of the full range of costs and benefits of a particular project;

- monetized assessment of identified costs and benefits;

- comparison of the total costs and benefits over the lifetime of the project in commensurate terms through their conversion to present value;

- comparing the results obtained with other projects and selecting the project that best meets investors' requirements.

Among the advantages of this method, which ensured its popularity, first of all, its versatility and ease of use are worth mentioning, as the entire list of costs and benefits is converted into monetary terms, which allows to estimate the aggregate long-term results of the project. On the other hand, this feature is limits the application of cost-benefit analysis in appraising projects with a wide range of arising social effects, as some of them are either partially amenable to monetised expression or are cannot be monetised.

The classic version of the cost-effectiveness analysis is similar in structure to cost-benefit analysis, but its distinctive feature is the expression of benefits in natural units and determination of the ratio of benefits per one monetary unit spent. The works of L. Yakobson are devoted to various aspects of this method (Yakobson, 2000). In general, the evaluation of investments using cost-effectiveness analysis is as follows:

$$
\mathrm{EE}=\frac{\Delta \mathrm{B}}{\Delta \mathrm{C}} * 100
$$

Where:

$\mathrm{EE}$ is the economic efficiency of the project,

$\Delta \mathrm{B}$ - incremental benefits,

$\Delta \mathrm{C}$ - incremental costs.

The main advantage of this approach is much less amount of the information required for the analysis. Costeffectiveness analysis is suitable for evaluating projects that aim to achieve certain results, the monetary evaluation of which is not possible, or is uncertain due to possible errors in calculations. For example, the World Road Organization recommends using this method for assessing the impact of transport investments on traffic safety (Colliard, 2014).

Having considered the general aspects of the above economic evaluation methods of transport investments, let us move on to the analysis of existing methodological recommendations on the appraisal of transport projects, which are both used in Russian and foreign practices.

\section{Methods}

The research in this paper relies on the use of systematic and comparative analysis tools to examine existing methodological recommendations for the appraisal of transport investments. In addition, the research is based on the results of economic studies devoted to the valuation of time as an economic resource.

\section{Comparative analysis of existing methodical guidelines for economic appraisal of transport investment}


We find the following documents most interesting from the perspective of the proposed tools and methods used to assess the wider economic impacts of transport projects, in particular evaluation of the travel time reduction benefits, which were selected for comparative analysis:

1) Transportation Cost and Benefit Analysis Techniques, Estimates and Implications (Litman, 2009);

2) DfT U. K. Transport Analysis Guidance. An overview of transport appraisal, Transport Appraisal and Strategic Modelling (TASM) Division;

3) Methodology for assessing the socio-economic effectiveness of the construction of new public railway lines (Pekhterev et al, 2009);

4) Methodology for assessing the socio-economic effects of construction (reconstruction) and operation of transport infrastructure projects planned for implementation with the involvement of the federal budget, as well as with the provision of state guarantees of the Russian Federation and tax incentives (2019).

First of all, it should be noted that the logic and sequence of the economic evaluation procedure in the above appraisal guidelines are similar in a number of fundamental points - the principles and main indicators of project efficiency evaluation are analogous. One of the differences is the range of arising effects and their distribution into categories. For example, the above-mentioned foreign methodologies (№ 1 and 2) pay special attention to the aggregate benefits of reduced travel time, including this effect in the category of direct results of transport project implementation. In particular, DfT U. K. Transport Analysis Guidance considers the effect of freeing up additional time resulting from reduced travel time as a fundamental source for the formation of external effects such as the impact of transport investments on the labor market, employment and the investment climate.

A special feature of this methodology, in contrast to the established practice of Russian approaches, is the initial assessment of the benefits of reducing travel time from the passengers' point of view, and only then the impact of these changes on the formation of external effects of the project is assessed.

The benefits of reduced travel time are calculated using the formulas below.

$$
G B=\left(S^{1}-S^{0}\right)(1+t)=\frac{1}{2}(1+t) \sum_{i j}\left(T_{i j}^{1}+T_{i j}^{0}\right)\left(P_{i j}^{1}-P_{i j}^{0}\right)
$$

Where:

GB - total benefits for passengers (work trips)

$\mathrm{S}$ - benefits for the passenger from the trip from point $\mathrm{i}$ to point $\mathrm{j}$;

$t$ is the average indirect tax rate on final consumption;

$\mathrm{T}$ is the number of trips between points $\mathrm{i}$ and $\mathrm{j}$;

$\mathrm{P}$ - the expected cost of the trip, (the cost of the travel ticket + the actual travel time $*$ value of passenger time).

The distinction between work and non-work trips is justified by the need to account for the indirect tax on the final product created, if the saved time on the business trip was reallocated to work activities. The upper index denotes the scenario under consideration - 0 is for the scenario without transportation project implementation, 1 is for the scenario with transportation project implementation (DfT, U. K., 2013).

Reducing general transportation costs makes trips more attractive to the passenger, which affects the number of trips and distance travelled, expanding the opportunities for passengers to benefit from the journey. Since faster travel implies an increase in transport fare, it is recommended to calculate time and financial elements of the total benefits for passengers separately. Such calculation prevents results distortion of the assessment of transport costs changes for passengers and makes it possible to assess the impact of transport investments on each of the elements of general transport costs.

This guidance is based on a cost-benefit analysis, and the valuation of travel time is carried out using the wage cost method, i.e. the value of passengers' time resources is considered primarily in terms of their income. The purpose of travel is also taken into account: working travel, i.e. carried out during the working day, and non-working travel, which includes travel to and from work, and any leisure travel. Benefits from the reduction in travel time for non-work trips are estimated at about half of this indicator for work trips.

Some travel conditions are also taken into account as determinants of passenger's willingness to pay for travel time reduction. For example, a passenger's willingness to pay for reduced waiting time outside the vehicle is approximately twice as high as the willingness to pay for reduced travel time in the vehicle. DfT U. K. Transport Analysis Guidance is used in evaluating any transportation project, so an additional factor in determining a passenger's willingness to pay for reduced travel time is the mode of transport whose choice is linked to passenger income levels.

Assessment of the effects arising from the reduction of travel time is also considered in Russian methodological documents related to the appraisal of the transport investments. Thus, in the methodological recommendations for assessing the socio-economic effectiveness of the construction of new public railway lines (№ 3) all observed effects are divided into direct, which are reflected in the financial results of the project participants, and external, determining the boundaries of the project impact. As part of the external effects in terms of their content, the most important are: 
- environmental (technological), which indirectly affect the standard of living of the population, (an increase or decrease of harmful emissions into the atmosphere and water bodies, soil pollution), etc;

- social, which are directly related to the standard of living of the population, i.e. affect the level of income of the population, the level of prices for goods and services, the cost of housing and utilities, lead to a change in working conditions. The social externalities also include savings or additional costs of free time of the population due to reduction of travel time.

As economic externalities are those impacts on business that are reflected in the financial performance of organizations not involved in the project, including changes in land and property values, the emergence of new production facilities, etc. Calculation of benefits from the reduction of travel time by passengers is carried out using the equation below:

$$
\mathrm{E}_{\mathrm{tt}}^{\mathrm{t}}=\mathrm{Q}_{\mathrm{pass}}^{\mathrm{t}} * \mathrm{C}_{\mathrm{pt}} *\left(\mathrm{~V}_{\mathrm{tt}}-\mathrm{V}_{\mathrm{tt}}^{\mathrm{C}}\right)
$$

Where:

$\mathrm{Q}_{\text {pass }}^{\mathrm{t}}$ is the number of passenger traffic in year $\mathrm{t}$;

$\mathrm{V}_{\mathrm{tt}}$ is the average journey time on a given section of railroad before the high-speed line was put into operation;

$\mathrm{V}_{\mathrm{tt}}^{\mathrm{C}}$ is the average journey time on the new high-speed line;

$\mathrm{C}_{\mathrm{pt}}$ is the cost of the passenger hour;

The economic sense of this consideration of the value of the time is that when transportation is accelerated, passenger diversion time from the sphere of material production is reduced. Accordingly, the economic effect of reduced travel time reflects the potential for the creation of a public product. The average hourly wage of a passenger in a given region is taken as the unit of measurement of benefits from the travel time saved by passengers. It should be noted that the construction of railway lines additionally takes into account the changes in travel time not only from the reduction in travel time on the railway line, but also the access time to the railway station, as well as the travel time to the center of the settlement.

The second of the above-mentioned Russian methodologies (№4) is used for the economic analysis of any transport projects in order to obtain a quantitative assessment of the increase in gross domestic product (GDP) and budget revenues in connection with the implementation of an infrastructure project. Its range of socio-economic effects that determine the increase in GDP includes: the effect of saving travel time for passengers and freight, the effect of improving the safety of passenger and freight transportation, the agglomeration effect and the increase in the output of goods and services as a result of the elimination of infrastructure constraints. Thus, the list of socio-economic effects does not include environmental effects, but additionally includes the agglomeration effect, which is formed due to the combination of high population density and increased transport accessibility.

Calculation of the economic effect of travel time savings is carried out using the following formulas:

$$
\mathrm{E}_{\text {ВРэан }}^{\mathrm{t}}=\left(\mathrm{TS}_{\text {pass }}^{\mathrm{t}}+\mathrm{TS}_{\mathrm{st}}^{\mathrm{t}}\right) * \mathrm{~W}_{\mathrm{CP}}^{\mathrm{n}} * \mathrm{P}_{\mathrm{i}=\mathrm{n}+1}^{\mathrm{t}}\left(1+\mathrm{I}_{\text {ИПЦ }}^{\mathrm{t}}\right) * \frac{12}{247 * 8}
$$

Where:

$\mathrm{TS}_{\text {pass }}^{\mathrm{t}}$ - is the release of passenger time due to the implementation of transport project in the year $\mathrm{t}$, hours;

$\mathrm{TS}_{\mathrm{st}}^{\mathrm{t}}$ - is the release of operating personnel time due to the implementation of transport project in the year $\mathrm{t}$, hours;

$\mathrm{W}_{\mathrm{av}}^{\mathrm{n}}$ - is the average monthly nominal wage of employees in the subject where the infrastructure project is implemented in the base year;

$\mathrm{P}_{\mathrm{i}=\mathrm{n}+1^{-}}^{\mathrm{t}}$ - is function of the product of $\left(1+\mathrm{I}_{\text {ИПЦ }}^{\mathrm{t}}\right)$;

$\mathrm{I}_{\text {ИПЦ }}^{\mathrm{t}}-$ is predicted consumer price index in the year $\mathrm{t}$, в percent;

12 - is number of months in the calendar year;

247 - is the average number of working days in a calendar year;

8 - duration of the working day, hours.

The release of passenger time is calculated as follows:

$$
T S_{\text {pass }}^{t}=N P_{\Pi \mathrm{IAC}}^{t} * T T R_{\mathrm{TC}}^{t} * \mathrm{~T}_{\text {pass }}
$$

Where:

$N P_{\text {pass }}^{t}$ - is the projected number of passengers of different transport modes due to the project implementation the year $\mathrm{t}$, people;

$T T R_{\mathrm{TC}}^{t}-$ is the travel time savings due to project implementation in the year $\mathrm{t}$; 
$\mathrm{T}_{\text {pass }}$ - the coefficient of passengers' use of time savings for economic activities.

The procedure for estimating the benefits of reduced travel time has also undergone significant changes. First, only the economically active population of the region is taken into account, rather than the number of passenger, in order to obtain more reliable estimates of the economic effect of additional time release. Second, the time release of both passengers and staff is also taken into account, using different coefficients in estimating the time released for work activities. A coefficient of 0.45 is used to estimate passenger time savings, which is consistent with the results of social surveys demonstrating that not every passenger uses the saved time for work activities; a coefficient of 1 is used to estimate staff time savings. The unit value of time is estimated through the average monthly nominal wage of the region, adjusted for the forecast consumer price index.

\section{Results and discussion}

To summarise the comparative analysis, the first thing to note is that Russian methodologies are increasingly using the estimation of travel time reduction in determining the effectiveness of transport projects. This is moving away from a focus on travel time savings for all passengers to a focus on savings for the economically active population. These assessments are supplemented by taking into account the emerging agglomeration effect, which is primarily determined by increasing population mobility and territorial connectivity. As we have already noted, the choice of foreign methodologies for comparative analysis was determined by the fact that the patterns of interest are highlighted most prominently in them. It should be emphasized that taking into account the time factor when assessing the efficiency of innovative transport investments is a global trend, which in our view is primarily due to the features of high-speed rail development the current stage.

Despite the in-depth theoretical justification and timely updating of the analysis tools used by the mentioned methodological recommendations, there are a number of uncertain positions in determining the value of travel time. First of all, it concerns the measurement of the socio-economic benefits from the transport projects implementation and, consequently, the assessment of the reduction of travel time. For example, the authors of Transportation Cost and Benefit Analysis Techniques are convinced that the impact of transportation projects on the socio-economic environment is so neglible that it can be ignored, and the total benefits resulting from a transportation project are distributed within the transportation industry. The emphasis on the category of benefits from the reduction of travel time in the context of evaluation of transport projects in general is characteristic of foreign economic appraisal practice. According to a number of experts, the value of benefits from the reduction of travel time in work trips is $50-70 \%$ of the total volume of aggregate results, depending on the specifics of the transport project. This is especially true for projects involving the organization of high-speed traffic. Thus, when estimating benefits from implementation of high-speed railway project in Australia, economic effect from reduction of travel time during 30 years of line operation was $52 \%$ of total benefits (AECOM et al., 2013).

It should be noted that some factors determining the value of reduction of travel time are overlooked. For example, they do not take into account travel conditions, which mean the level of passenger comfort, the availability of productive use of time, as well as the successive stages of transportation, which are characterized by different values of time. Transportation Cost and Benefit Analysis Techniques, Estimates and Implications considers these factors and proposed the use of relative values derived from scientific researches to estimate them. Although relative values may vary from project to project, they are essential in order to develop universal tools for estimating benefits of transport investments. For example, a trip under discomfort conditions is characterised by increased value of the passenger's willingness to pay for reduced travel time - approximately $120-150 \%$ of the value of this indicator when travelling under normal conditions. The possibility of productive use of time, on the contrary, contributes to a decrease in the willingness to pay for a reduction in travel time.

Most passenger transportation is performed using several modes of transport during a single trip, so it is worth considering not only the reduction in travel time by the main mode of transport, but also the time required to reach the place of departure, vehicle change, waiting time, and so on (Lyakina et al., 2018). Each of the stages of a trip can be characterised by a different value of travel time reduction, depending on how the passenger evaluates the quality of transport service provided. A high level of willingness to pay for travel time reduction indicates passenger dissatisfaction with the quality of the transport service provided, and vice versa. The different value of the reduction in travel time for the stages of journey makes it fundamentally important to account for changes in transport costs of the passenger not only by the main mode of transport, but also for the entire trip. If a trip involves the use of multiple modes, the willingness-topay rate for the reduction in time spent changing modes is approximately $150 \%$ of the value of the travel time reduction by the main mode of transportation.

Closely related to the estimation of time resources is the problem of ambiguously determining the formation mechanism of externalities from reduced travel time. The benefits of reduced travel time are assessed primarily from the perspective of using the time freed up for work. A fairly common scheme is the full estimation of benefits from the reduction in business travel time with monetisation by average regional wages or GDP per capita. 
However, not all economists agree with this notion of the value of time resources and their transformation into various economic benefits. Thus, D. Metz in his work notes that the hypothesis of saved time redistribution by passengers to carry out other activities is not confirmed in practice (Metz, 2008). The concept of the value of time is based on the rule of utility maximisation - time is a limited, non-renewable resource, for the preservation of which people are willing to incur additional costs. Advances in science and technology, combined with rising incomes, have made it possible to move more quickly over greater distances. It was originally assumed that transport investments would reduce the amount of time needed to travel, and the passengers would use the time saved for more useful, from their point of view, activities. In this case, the amount of time spent by passengers on trips should steadily decrease. However, empirical research shows a very different picture - from 1970 to 2010 the average duration of daily trips made by passengers in the UK is almost unchanged and amounts to about 1 hour per day. Moreover, the average range of trips made during this period has increased by almost $60 \%$.

In our view, from the perspective of society as a whole, a reduction in travel time can be seen positively for the following reasons. The first is the potential increase in GDP if the saved time is used for work activities. If the saved time is used for personal or leisure activities, the positive effect of saving time will be an increase in public welfare. Consequently, the benefits of reduced travel time extend not only to passengers using public transport services but also to society as a whole. In this regard, the accounting of benefits from the reduction of travel time can be carried out not only through the analysis of changes in GDP (GRP), but also through the analysis of economic welfare.

The necessity to take into account the benefits from the reduction of travel time using two methods is indicated by the specifics of transport projects, the impact of which goes beyond the usual framework of the market. For example, an alternative indicator of GDP - the genuine progress indicator takes into account the total transport costs of passengers as one of the "social" components, which reflect the life quality of the population.

The fundamental economic theory of the individuals' behavior on the allocation of time can be traced back to the pioneering work of Becker (Becker, 1965) and De Serpa (DeSerpa, 1971). For example, G. Becker argued that household members seek to maximise the utility of time by allocating it rationally between work and household work. In this approach, the value of time was considered from the position of foregone benefits from any activity except work. Here it is worth noting an important factor determining the attractiveness of transportation services for the passenger, the interpretation of which has undergone significant changes since the concept of time as an economic resource emerged. We are talking about passengers' perception of travel time as wasted and necessary only for the journey. With the development of information and communication technology, passengers now have the opportunity to use their travel time more productively. This is especially true for rail transport, where passengers can work, study, or simply relax using personal gadgets. As several social studies show, such an opportunity for productive use of time in journeys contributes to a change in the value of reducing travel time, respectively, reducing the willingness of the passenger to incur additional financial costs for a faster movement (Crozet and Mercier, 2018). Similar conclusions were reached by the authors of the other study the results of which showed that people do not always have the opportunity to use the saved time, and since time is not subject to accumulation, unlike money, passengers are more concerned about the loss of travel time due to the inability to perform any activity during the trip, rather than about an increase in free time (Shiaw, 2004). The authors of the study considered only non-work trips, so the results of their study are irrelevant to the assessment of time savings on work trips.

Another study aimed at assessing the impact of the possibility of productive travel time on the attractiveness of the transport service for the passenger has shown that the upper limit of the reduction in the value of travel time reduction from the development of information and communication technologies is about 20\% (Kouwenhoven et al, 2019). Consequently, for passengers it is important not only to have the direct reduction of travel timed, but also the possibility of productive use of time in the journey. This factor may be the reason why the average duration of daily trips is not decreasing, despite the development of transport technologies that provide faster travel. Because such "multitasking" allows passengers to obtain certain benefits not only at the destination point for which the trip was made, but also the benefits of productive use of time on the way. Thus, the value of the benefits from performing activities while traveling is equal to the value of reducing travel time, otherwise we would see a downward trend in the average duration of daily trips.

Consequently, we can assume that the benefits from the reduction of travel time are not in the redistribution of the saved time, but in an increase in transport accessibility and mobility of the population, which expands opportunities for passengers to choose jobs, places of residence, recreational activities, and so on. This assumption does not invalidate the fact that time savings contribute to the formation of economic benefits, but in this case, the procedure for evaluating transportation projects should focus not on the monetary value of additional products and services due to the redistribution of the saved time for work activities, but on assessing the benefits of induced demand for transportation.

At this point, the question of how the time saved is allocated in the long run - to work/leisure activities or to additional travel - remains open. To shed light on this problem can help studies that will take into account the change in the behavioral mechanisms of passengers in the long term due to changes in transport accessibility. We emphasize that if there is a trend towards higher population mobility, there will be a more pronounced formation of agglomeration effects, in particular through increased pendular migration between large socio-economic centers with a developed transport infrastructure. 
In our opinion, the mechanism of the external effects formation from the reduction of travel time can be presented as follows.

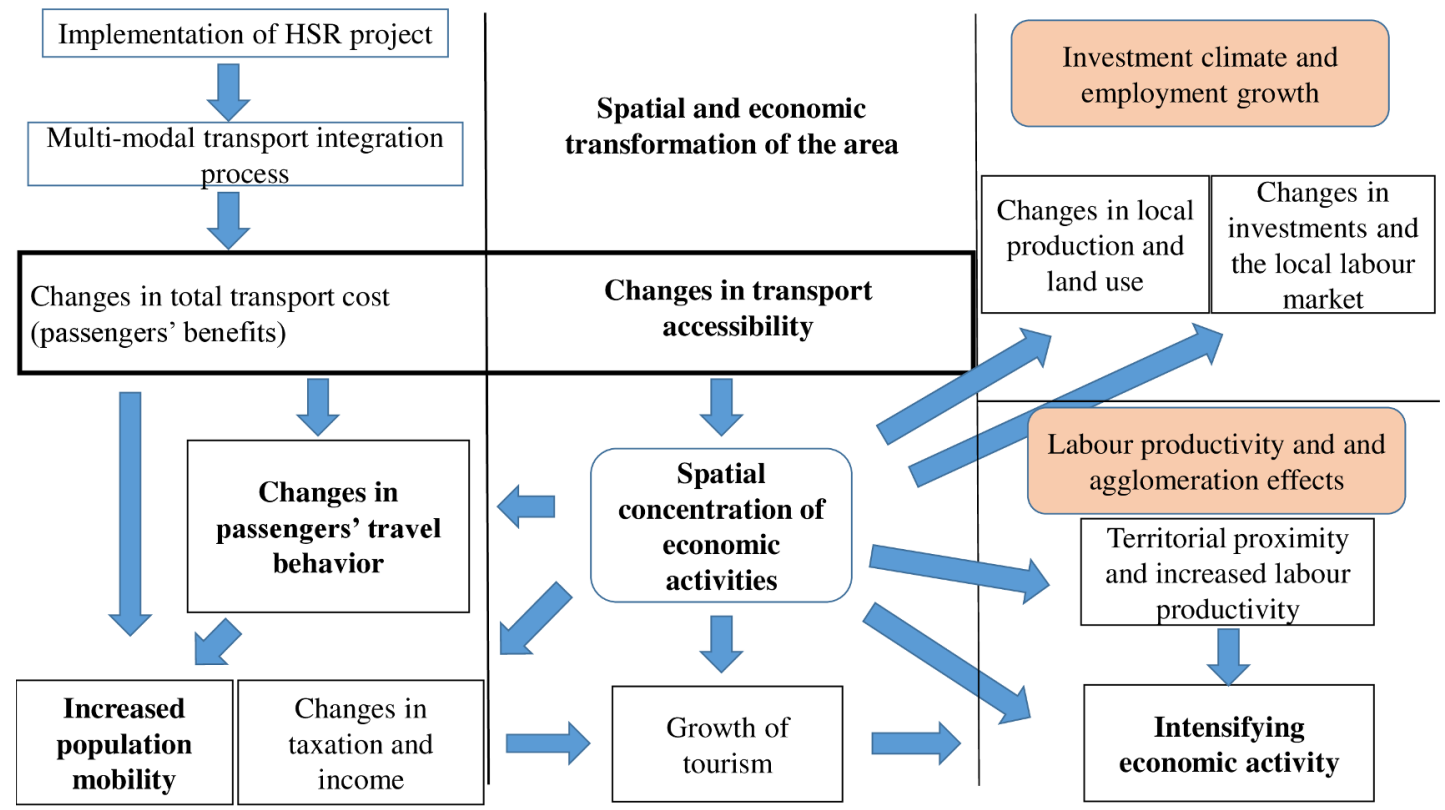

Figure 1. The formation mechanism of external effects from improved transport accessibility.

A direct result of the HSR project implementation is an increase in transport accessibility, which means a reduction in travel time. The reduction of travel time makes trips more profitable for passengers, which tends to increase the population mobility. Increased population mobility can be transformed into both an increase in business trips and an increase in leisure travel (tourism). Consequently, an increase in the number of tourist trips will contribute to the development of this industry, which is reflected in the budget revenues.

Due to improved transport accessibility, high-speed rail transport ensures the free movement of people, contributing to the gradual concentration of resources in cities connected to the high-speed rail system. On the one hand, the territorial concentration of resources guarantees the economic development of the area. On the other hand, it attracts manufacturers (lower transport costs, concentration of production factors, wide consumer coverage), investors (higher rates of economic development in the area), and the population (lower transport costs, high demand for labor resources, including qualified specialists). The combination of high population density and territorial proximity is a factor of increasing productivity. The change of investment climate through the increase in the number of enterprises and intensification of economic activity has its impact on the value of land located near the transport infrastructure, which promotes national wealth growth.

\section{Conclusion}

The analysis of the reviewed guidelines for economic appraisal of transport investment and practice of HSR projects implementation allowed us to conclude that the importance of benefits from reduced travel time in determining project effectiveness has increased.

The article substantiates the key importance of total passenger benefits that determine both the payback period of the transport project and facilitate the formation of external effects from the implementation of the transport project due to changes in transport accessibility.

The value of reduced travel time to the passenger has been shown to be significantly affected by the factor of comfort, including the possibility of productive time use.

It has been proved that the value of travel time in the general transport costs is fundamental to the formation of external effects, which determines the priority of its assessment in the context of economic analysis transport projects.

A visual model of the socio-economic effects formation of the HSR project, caused by changes in the passengers' total transport costs and increased transport accessibility of the region, is proposed. 


\section{References}

1. AECOM, GRIMSHAW, KPMG, SKM, ACIL Tasman, Booz\& Co and Hyper, High-speed Rail study. Phase two report. Sydney. -2013

2. Atkinson, A., \& Stiglitz, J. (1980). Lectures on Public Economics McGraw-Hill. New York.

3. Batley, R., Bates, J., Bliemer, M., Borjesson, M., Bourdon, J., Cabral, M. O., Worsley, T. (2019). New appraisal values of travel time saving and reliability in Great Britain [Article]. Transportation, 46(3), 583621. https://doi.org/10.1007/s11116-017-9798-7

4. Becker, G. S. (1965). A Theory of the Allocation of Time. The economic journal,75(299), 493-517. https://doi.org/10.2307/2228949

5. Colliard, J. (2014). Evaluation of measures, recommendations and guidelines for further implementation. Pilot Test, 8 .

6. Crozet, Y., \& Mercier, A. (2018). Urban toll: Rethinking acceptability through accessibility.

7. Kouwenhoven, M., de Jong, G. C., Koster, P., van den Berg, V. A. C., Verhoef, E. T., Bates, J., \& Warffemius, P. M. J. (2014). New values of time and reliability in passenger transport in The Netherlands [Article]. Research in Transportation Economics, 47, 37-49. https://doi.org/10.1016/j.retrec.2014.09.017

8. DeSerpa, A. C. (1971). A theory of the economics of time. The economic journal, 81(324), 828-846. https://doi.org/10.2307/2230320.

9. DfT, U. K. (2013). Transport Analysis Guidance. An overview of transport appraisal, Transport Appraisal and Strategic Modelling (TASM) Division-2014.

10. Gramlich, E. M. (1981). Benefit-cost analysis of government programs. Englewood Cliffs, NJ: Prentice-Hall.

11. Hansen, B. O., Hougaard, J. L., Keiding, H., \& Osterdal, L. P. (2004). On the possibility of a bridge between CBA and CEA: comments on a paper by Dolan and Edlin [Article]. Journal of Health Economics, 23(5), 887898. https://doi.org/10.1016/i.jhealeco.2003.10.002

12. Hensher, D. A. (2011). Valuation of travel time savings. In A. DePalma, R. Lindsey, E. Quinet, \& R. Vickerman (Eds.), Handbook of Transport Economics (pp. 135-159). Edward Elgar Publishing Ltd.

13. Kovacikova, T., Lugano, G., \& Pourhashem, G. (2018). From Travel Time and Cost Savings to Value of Mobility [Proceedings Paper]. Reliability and Statistics in Transportation and Communication, 36, 3543. https://doi.org/10.1007/978-3-319-74454-4 3

14. Litman, T. (2009). Transportation cost and benefit analysis. Victoria Transport Policy Institute, 31, 1-19.

15. Lyakina, M., Volkova, E., \& Tretyak, V. (2018). Application of digital economy global trends in russian transport systems. Proceedings of the 18th International Scientific Conference Globalization and Its Socio-Economic Consequences, Rajecke Teplice, Slovak Republic, 2214 - 2219.

16. Lyons, G., Jain, J., \& Holley, D. (2007). The use of travel time by rail passengers in Great Britain [Article]. Transportation Research Part a-Policy and Practice, 41(1), 107120. https://doi.org/10.1016/j.tra.2006.05.012

17. Metodika ocenki social'no-ekonomicheskih effektov ot proektov stroitel'stva (rekonstrukcii) i ekspluatacii ob"ektov transportnoj infrastruktury, planiruemyh $\mathrm{k}$ realizacii s privlecheniem sredstv federal'nogo byudzheta, a takzhe s predostavleniem gosudarstvennyh garantij Rossijskoj Federacii i nalogovyh l'got: Postanovlenie Pravitel'stva RF ot 26.11.2019 N 1512

18. Metz, D. (2008). The myth of travel time saving [Article]. Transport Reviews, 28(3), 321336. https://doi.org/10.1080/01441640701642348

19. Meunier, D., \& Quinet, E. (2015). Value of Time estimations in Cost Benefit Analysis: the French experience [Proceedings Paper]. Current Practices in Transport: Appraisal Methods, Policies and Models, 42nd European Transport Conference Selected Proceedings, 8, 62-71. https://doi.org/10.1016/j.trpro.2015.06.042

20. Mishan, E. J., \& Quah, E. (2020). Cost-benefit analysis. Routledge.

21. Ojeda-Cabral, M., Hess, S., \& Batley, R. (2018). Understanding valuation of travel time changes: are preferences different under different stated choice design settings? [Article]. Transportation, 45(1), 121. https://doi.org/10.1007/s11116-016-9716-4

22. Pekhterev, F. S., Livshic, V. N., Pugacheva, A. A., \& Macheret, D. A. (2009). Metodika ocenki social'noekonomicheskoj effektivnosti stroitel'stva novyh zheleznodorozhnyh linij obshchego pol'zovaniya.

23. Shiaw, M. S. (2004). Value of leisure time based on individuals' mode choice behavior [Article]. Journal of Advanced Transportation, 38(2), 147-162. https://doi.org/10.1002/atr.5670380204

24. Wardman, M., Batley, R., Laird, J., Mackie, P., \& Bates, J. (2015). How should business travel time savings be valued? Economics of transportation, 4(4), 200-214. https://doi.org/10.1016/j.ecotra.2015.08.003

25. Yakobson, L. I. (2000). Gosudarstvennyj sektor ekonomiki: ekonomicheskaya teoriya i politika. TACIS. 